\title{
Digital transformation: the case of the application of drones in construction
}

\author{
Irina Zaychenko ${ }^{1, *}$, Anna Smirnova ${ }^{1}$ and Alexandra Borremans ${ }^{1}$ \\ ${ }^{1}$ Peter the Great St.Petersburg Polytechnic University, Polytechnicheskaya, 29, St. Petersburg, \\ 195251, Russia
}

\begin{abstract}
The article deals with a relatively recent, but dynamically developing branch of the economy-the digital economy. A brief historical review of the formation of this direction, its impact on the traditional economy. On the basis of statistical data, the analysis of the potential of its development and the impact of the digital economy on the structure of modern innovative firms. As a comparative model, an in-depth analysis of the effectiveness of the introduction of modern digital technologies is carried out on the example of the use of three-dimensional modeling of extended objects in the construction industry using multi-dimensional scanning produced by unmanned aerial vehicles (drones) equipped with laser scanning systems and automatic positioning systems with reference to the terrain by GPS coordinates.
\end{abstract}

\section{Introduction}

The term "digital economy" was first used relatively recently, in 1995, by an American scientist from the University of Massachusetts Nicholas Negroponte to explain to colleagues the advantages of the new economy in comparison with the old one in connection with the intensive development of information and communication technologies [1].

The core of the digital economy is the sector of digital goods and services related to digital technologies. Statistics of OECD countries, despite the global instability, shows a steady growth in world trade in digital economy products (on average, growth is about $4 \%$ ), faster growing volume of services (up to $30 \%$ per year) [2]. Enterprises spending on research related to digital technologies are increasing, indicating that the digital sector plays a key role in innovation. Digital infrastructure is developing and becoming more accessible as the quality of communication networks increases with the introduction of $4 \mathrm{G}$ technologies and fiber optic data transmission, while prices, in particular, for mobile communication services, the possibility of using mobile devices for Internet access increases, which ultimately allows to predict the increasing coverage and development of digital technologies in the world [3].

\section{Materials and methods}

\footnotetext{
* Corresponding author: olgakalinina@,bk.ru
} 
The aim of the study is to study the aspects of digitalization of the economy on the example of the use of drones in construction. In the course of the research such General scientific methods as analysis and synthesis, methods of classification, comparison were used.

When writing this article, scientific and literary materials, articles in periodicals and Internet resources were used. Overview of scientific literature digital business can be divided into three groups. The first group work [6-13] is devoted to justification of relevance of methods digital business transformation and is a general nature. "Digital economy - various ways to effective use of technologies" that shows that the digital economy is a future step of development of the global economic system due to transformation of all human activity under the influence of information and telecommunication technologies. The level of spread of the Internet and other innovative technologies demons the ability to ignore their impact on the world economy. There is considerable potential for the use of modern digital technologies in firms. It is important to pay attention to such aspects as the use of modern computer technology, software, availability of qualified specialists. It should be taken into account that digital technologies have a significant potential to accelerate innovation processes, so the indicators of investment in the development of the digital potential of the firm are an important factor in its competitiveness in modern conditions.

The second group work [13-20] reveals questions business only in terms of management human resources. The latter group works examines questions of methods digitalization in banking. Thus, it is possible to state that currently there are research that demonstrates demand for this subject, as scientific and technical progress and the development of society change the behavior and thinking consumers that challenges new approaches to the transformation of business. It is, modern consumer and culture communications is the driver changes business processes.

The main features of digital economy determine the following:

- financial activities focuses on the platforms "digital" economy;

- personalized service model;

- direct interaction producers and consumers;

- the spread of the economy sharing;

- a significant role of the contribution of individual members.

In the conditions of digital economy information become a form of capital, and financial benefits get the company, which have not only a tolerance to the information, but also effective technology their transformation and applications. The main objectives of business management becomes the acquisition of information about his stay in real-time and management on their based financial processes. Directly this ensures information management. Important condition prosperity in the digital economy become the new model management technology, processes and information, allowing to implement prompt response and forecasting upcoming calls and problems. Modern digital technology all penetrate the structure of this business. They all closer integrated with the production and administrative processes companies, all rapidly used functional units companies in their own activity and in the relationship with located around the society. The presence of modern it infrastructure corresponding to business needs of the company - is an objective the need of this business [6-8].

\section{Results}

Emerging new business models and network structures based on collective production and consumption methods are transforming traditional market relations and require new solutions in the management of a modern firm. The further development of digital technologies is important for the whole economy. To describe all the new features that will be presented below, first consider the" three waves " of the digital age [4]. 


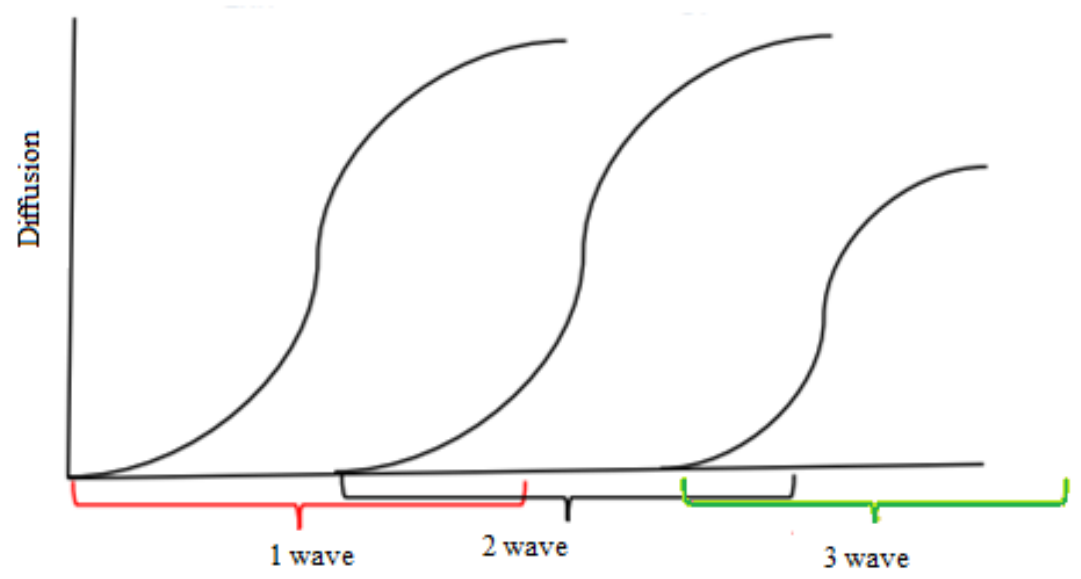

Fig. 1. Digitization technology waves.

1 wave : it computerization (including personal), process automation (ERP, EDI, CRM, etc.),telecommunications: wired broadband, wireless broadband

2 wave Online platforms (search engines, trading platforms, distance learning, social networks) Cloud computing

3 wave Predictive Analytics of big data Internet of things $\S$ Robotics $\S$ Additive technologies (including 3D printing) Artificial intelligence (including machine learning)

One of the striking examples of the third wave is the use of robotics, one of the types of which is an unmanned aerial vehicle (drone) [5]. Companies are beginning to understand that sometimes to get the best results you need to go up in the sky.

The use of commercial drones in a variety of industries is gradually gaining momentum, as companies are interested in using advanced technologies and reducing hardware costs for the introduction of technologies in their workflows.

Drones have emerged as a highly effective commercial tool for application in many sectors, most notably in construction, writes in his article John Patterson (UK). This is not surprising, since their application vary from security tasks on the construction site up the ability to monitor projects that previously were impossible. The market, which in the coming years will be estimated at billions of dollars, does not deny the ever-growing importance of commercial drones [6-7].

All aspects of the business - from agriculture to entertainment and media-take full advantage of unmanned aerial vehicles. However, one of the fastest growing sectors is infrastructure development, which includes construction. The following diagram (figure 2) shows which industries are the largest players in the commercial UAV market . 


\section{Drone usage by industry sector}

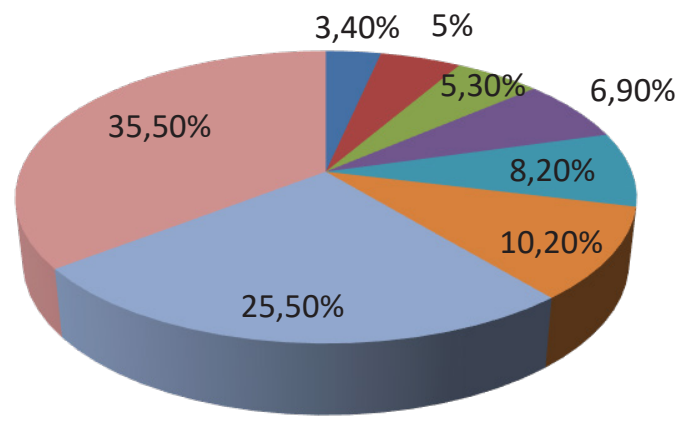

mining industry

telecommunications

- insurance

media

safety

transport

agriculture

Fig. 2. The use of drones in the sectors of the economy.

At the moment, the construction industry is the second largest in the world after agriculture, its volume is $\$ 8$ trillion per year. However, it is extremely inefficient. According to McKinsey's research, commercial construction projects often exceed the budget by $80 \%$, and deadlines-by 20 months [8-9].

On paper and on the computer everything looks great. But in reality, in the bustle and dirt of the construction site, everything is different. In this gap between plans and reality, about three out of eight trillion dollars are lost - they are lost in the flow of recalculations, alterations and deviations from the schedule. This situation can help to decide the drones.

\section{Drones in construction}

The success of drones in the construction sector is due to their well-thought-out implementation by many large companies.

In the construction industry, unmanned aerial vehicles provide easy access to large or hard-to-reach facilities, as well as to complex or high-rise facilities. They are able to provide aerial photography data, map information and images used for:

- land surveying;

- building inspections;

- provide visual materials to customers and employees;

- monitoring the progress of work on the construction site;

- security control;

- mappings.

What the future of the construction industry looks like thanks to the growth of intelligent solutions, automation and the use of unmanned aerial vehicles [10-13].

\section{Creation of information models (BIM)}

$\mathrm{BIM}$ is the process of creating and managing information about a construction project throughout its life cycle. It creates a joint digital description of each aspect of the structure, which can be updated by all relevant actors. Drones contribute to this process in a variety of ways, including [13-14]. 


\section{3D-modeling}

3D models of large areas or objects can be quickly created using drones and combined with laser scanning and standard topographic survey. Usually the calculation of the volume of excavation requires a lot of time from the engineer-surveyor. It is necessary to have a special layout of the pit or trench, to determine the elevation of the characteristic points, to perform calculations. As the authors of the development say, the solution of this problem will require minimal actions from the engineer-to specify the area on the construction plan with the mouse and wait for the completion of the shooting.

\section{Keeping the project on-track, on-budget}

By identifying the parts of the project that are going off-track, having the ability to prevent any causalities, rigorously monitoring your job sites; you will be much better prepared to remove any additions to project time and cost.

As many project managers know, real-time control is some of the most difficult to keep a handle on. The more information you have at your fingertips, the more control you have over your project ultimately. If something goes wrong on the site, you will lose drastically less money if you can correct the problem very quickly [14-18].

Making crucial decisions about when a project is going to close is essential to the stoppage of cash flow that can literally bleed during this juncture of building.

Using drones allows you to have more real-time detailed control over the project, so you can keep track of the progress visually, and achieve closure at perhaps a quicker time then previously estimated.

Looking back to see what went well on a project and what did not is one of the most important ways to figure out what can be done in the future for profitability, and will help the manager figure out how to execute other projects more efficiently[17].

Looking for drones construction applications can always shape the next step in your business massively, and help you as the boss keep your eyes out for other ways to generate revenue, and other ways to make things operate at a higher standard.

\section{Orthomosaic}

High-resolution aerial photographs can be taken over the entire project area and all images can be combined to form a complete mosaic. These data can be used to obtain an idea of the construction zone and its corresponding parameters.

\section{Automated construction sites}

In the spring of 2018, China's leading manufacturer DJI announced the largest order in history for commercial drones. Partnering with the American technology company Skycatch is an unprecedented delivery that sets a noteworthy benchmark for construction firms around the world. The Japanese construction giant Komatsu will receive 1,000 aircraft to inspect and monitor its projects [16-20].

Boosting business development and marketing efforts

One of the primary reasons aerial photography is the number one use of commercial drones is because of the value to executive and marketing teams.

Insights from drones can help executives improve safety, project efficiency and data accuracy. On the marketing side, aerial photography and video for marketing residential and commercial real estate is one of the best-known applications for drones. Rather than hiring a 
crane or helicopter, many firms are choosing to spend far less money to hire a drone with a high-quality camera and a capable pilot to capture photos showing the potential view of a given office, even before the office tower has been built [21].

With a drone, companies can achieve unused angles, capture the aerial perspective, and get results that would otherwise be impractical or impossible. This creates a competitive advantage when it comes to promoting a firm's projects and services.

The negative aspects of the use of drones in the construction industry include such indicators as:

- you need to think about the tasks in advance. There are no two identical construction sites, as well as the same difficulties with them;

- you need to have a clear idea of what you will do with the information before you collect it, as this will allow you to select the level of detail required to perform the task;

- ensure compliance with the requirements of the Federal civil aviation administration ;

- train your staff or resort to the help of licensed pilots.

\section{Conclusion}

In conclusion, we can say that the drones can be used in any industry dealing with geographically extended objects, the state of which you need to monitor-gas pipelines, electricity, Railways, etc., it should Also be noted that the use of unmanned aerial vehicles has both obvious advantages and a number of disadvantages

The advantages of using drones include such factors as:

- reducing the cost of surveyors;

- inspection of construction sites during disasters;

- reduced resource costs;

- faster data collection leads to higher returns.

The negative aspects of the use of drones in the construction industry include the following indicators:

- It is necessary to think over tasks of works in advance;

- There are no two identical construction sites, as well as the same difficulties with them;

- You need to have a clear idea of what you will do with the information before you collect it, as this will allow you to select the level of detail required to perform the task;

- ensure compliance with the requirements of the Federal civil aviation administration ;

- train your staff or resort to the help of licensed pilots.

\section{References}

1. R. Katz, Socio-economic impact of digital transformation on the economy, ITU discussion paper, GSR-17.2017https://www.itu.int/en/ITUD/Conferences/GSR /Documents/ GSR2017/ Soc_Eco_impact_Digital_transformation_finalGSR.pdf

2. Digital economy: how experts understand the term, RIA Novosti-2017, https://ria.ru/science/20170616/1496663946.html

3. A.P. Dobrynin, Yu. Black, P. Chuprynousky, International journal of open information technologies 1(4), 4-10 (2016)

4. T.N. Yudina, Theoretical Economics 3, 12-16 http://open.gov.ru/events/5515775/

5. I. Ilin, S. Shirokova, A. Lepekhin, E3S Web of Conferences 33, 030072017 (2018) 
6. URL : https://blog.appdynamics.com/engineering/digital-transformation-in-theconstruction-industry/

7. URL: https://www.bcg.com/publications/2016/engineered-products-infrastructuredigital-transformative-power-building-information-modeling.aspx

8. URL : https://inform.tmforum.org/internet-of-everything/2017/01/drones-applicationsfuture .

9. J. Unger, M. Reich, C. Heipke, International Archives of Photogrammetry, remote sensing and spatial information science XL-5, 601-606 (2014)

10. R.C. Erenoglu, O. Akcay, O. Erenoglu, Journal of cultural heritage 26, 79-90 (2017)

11. S. Herlitschka, D. Valtiner, Elektrotechnik und Informationstechnik 134(7), 340-343 (2017)

12. P. Doucek, J. Fisher, Digital economy math., 2017 IDIMT 2017: Digitalization in management, society and economy - 25 Interdisciplinary negotiations on information management, 33-40 (2017)

13. A. Polyanin, T.V. Golovina, I. Avdeeva, I.V. Dokukina, Yu, Vertakova, Proc. of the 30th Int. business, Association information management conf., IBIMA 2017 - vision 2020: sustainable development, innovation management, and Global growth, 1792-1803 (2017)

14. URL : http://vo-vremya.ru/stati/it/cifrovaya-ekonomika-chto-eto

15. URL : https://www.hse.ru/primarydata/ice 2017

16. URL : http://www.oboznik.ru/?p=57817

17. I. Ilin, A. Lepekhin, A. Levina, O. Iliashenko, Advances in Intelligent Systems and Computing 692, 1306-1314 (2018)

18. URL :

http://apps.webofknowledge.com/full_record.do?product=WOS\&search_mode=Gener alSearch\&qid $=14 \&$ SID $=$ E2BkKx6tsYOfpV2uj8F \&page $=9 \&$ doc $=83$

19. URL :

http://apps.webofknowledge.com/full_record.do?product=WOS\&search_mode=Gener alSearch\&qid $=2 \&$ SID $=$ E2BkKx6tsYOfpV2uj8F\&page $=6 \&$ doc $=51$

20. A. Levina, I. Ilin, R. Esedulaev, IT Requirements Integration in High-Rise Construction Design Projects 33, 030092017 (2018) 